\title{
Cancellation of elective surgical procedures in the Genito-Urinary section of National Hospital of Sri Lanka - can we do better?
}

\author{
Gayathri Charika Hewawasam $^{1} *$, Ayesha Maduwanthi ${ }^{1}$ \\ Regsitrar in Anaesthesiology ${ }^{I}$, National Hospital of Sri Lanka. Colombo. Sri Lanka.
}

*Corresponding author: gaya3hewawasam@live.com

\begin{abstract}
Background
Cancellation of elective surgical procedures on the day of surgery is a parameter to assess the quality of patient care and the quality of the management system. There are many reasons for cancellation of elective surgical cases; and they differ from unit to unit and hospital to hospital. There are many causes such as medical, surgical, administrative, anaesthetic and patient factors.
\end{abstract}

\begin{abstract}
Materials and Method
We prospectively collected data over a four month period from May to August 2012 in the Genito-Urinary section of National Hospital of Sri Lanka to determine the prevalence and causes for cancellation of elective surgical procedures.

\section{Results}

1724 patients were scheduled for elective surgical procedures during the study period; $106(6.0 \%)$ of these were cancelled on the day of surgery. $16.9 \%(18 / 106)$ of patients defaulted admission. Majority of the cancellations were within the $61-70$ year age group $(31.1 \%)$ The cancellations of major, intermediate and minor surgeries were $58.5 \%$, $18.9 \%, 22.6 \%$ respectively.

\section{Conclusion and Recommendations}

Ideally there should be no cancellations. Cancellations can be minimized if the patients with medical problems were detected early and referred for an anaesthetic assessment soon after they are scheduled for surgery. Cancellation due to lack of theatre time should be minimised with proper planning. It is worth looking at why nearly $17 \%$ of patients defaulted. There may have been problems with communication. Minimising cancellations will improve operating room efficiency and reduce wastage of time and money.
\end{abstract}

Keywords: cancellation; elective surgical list

\section{Introduction}

An operation theatre is the heart of a hospital requiring considerable human resources and expenditure from the hospital budget. However, operation theatres are underutilized and lie idle some of the time and many patients who are called for operation from waiting lists are not operated upon. Planned operations that are cancelled reflect inefficiency in management and causes inconvenience to patients.

Cancellation of operations presents a major problem in most hospitals. There are many reasons for cancellation of elective surgical cases. Cancellation of cases on the scheduled day of surgery leads to inefficient utilization of manpower and scarce resources. It also leads to prolonged hospital stay, and in many cases, repetition of the various aspects of preoperative preparation and management. All of these inconvenience the patient as well as increase patients' treatment expenses. This leads to emotional distress and economic ramification for both patients and institution. There is evidence that preoperative assessment in an anaesthesia clinic can reduce the cancellation of elective patients. An exception would be a patient who experiences an adverse medical event or illness between the time of evaluation and the time of the planned surgery. Avoidance of unnecessary cancellation of elective surgery, therefore, should lead to a reduction in the overall cost of treatment.

We conducted a prospective study to determine the reasons for cancellation of genitourinary 
surgical inpatients on the day of surgery in the National Hospital of Sri Lanka. The purpose of this audit was to assess the incidence, causes and pattern of cancellation of elective surgery in the genito-urinary section of our hospital. Our aim was to suggest improvements to the system to reduce such cancellations which will enhance efficiency and minimize wastage of already limited resources and manpower.

\section{Material and methods}

This study was conducted over a period of four months from May to August 2012 in the genitourinary section of the National Hospital of Sri Lanka. Majority of our surgical patients undergo a preoperative assessment in the wards the day before surgery. Patients that are booked by the surgeon are admitted a day before or on the day of surgery. Preoperative assessment of these patients is then done in the operation theatre. A data collection form was distributed to the operating theatre and attending medical officers and nurses were asked to fill it up. The data recorded included the total number of operations performed in the study period, the number cancelled and reasons for cancellation. Cancellation reasons were entered into the database as coded variables.

\section{Results}

1724 patients were scheduled for elective surgical procedures during the study period; $106(6.0 \%)$ of these were cancelled on the day of surgery. The causes were coexisting medical problems $38.7 \%$ (41/106), administrative $25.5 \%$ (27/106), patient related $18.8 \%(20 / 106)$, surgical $12.2 \%$ (13/106), and anaesthesia related 2.8\% (3/106). Out of the medical problems which led to cancellation were commonly: acute cardiac causes $17.9 \%(19 / 106)$ and acute respiratory causes $9.4 \%$ (10/106). From the administrative causes $17.9 \%$ (19/106) were due to lack of theatre time. Out of the patient related causes $16.9 \%$ (18/106) were because the patient failed to admit. According to the age group cancellations were mostly within the $61-70$ year age group (31.1\%) \& 51 - 60 year age group (25.4\%). The cancellations of major, intermediate \& minor surgeries were $58.5 \%, 18.9 \%, 22.6 \%$ respectively.

\section{Analysis of results}

Figure 1: Complexity of surgery

\begin{tabular}{|l|l|l|l|l|l|l|}
\hline & \multicolumn{2}{|l|}{ Major } & \multicolumn{2}{l|}{ Intermediate } & \multicolumn{2}{l|}{ Minor } \\
\hline & $\begin{array}{l}\text { Total } \\
\text { No }\end{array}$ & Cancelled & $\begin{array}{l}\text { Total } \\
\text { No }\end{array}$ & Cancelled & $\begin{array}{l}\text { Total } \\
\text { No }\end{array}$ & Cancelled \\
\hline Total & 519 & 62 & 368 & 20 & 837 & 24 \\
\hline
\end{tabular}

Figure 2: Operations scheduled and cancelled

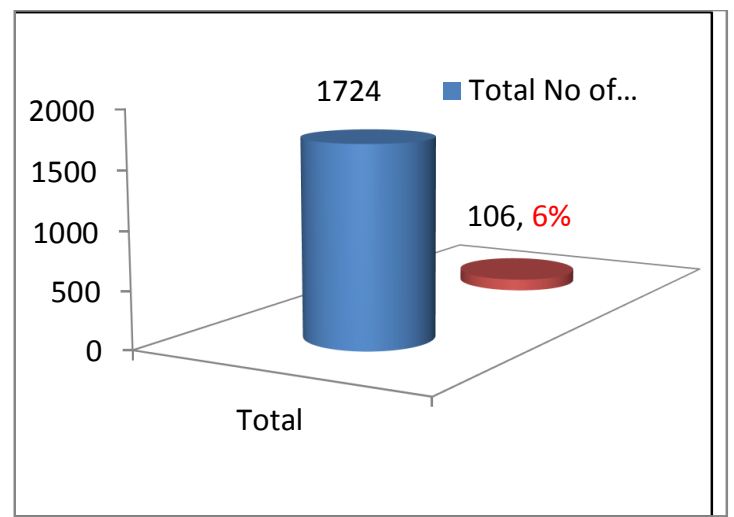

Figure 3: Operations performed and cancellations

- Operations performed $\square$ No of Cancellations

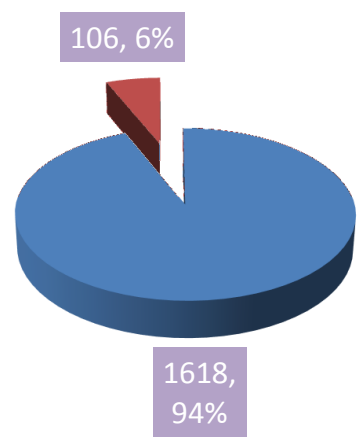




\begin{tabular}{|l|l|}
\hline Reasons for Cancellations & Number of Cancellations \\
\hline Medical & 41 \\
Administrative/ Logistic & 27 \\
& \\
Patient related & 20 \\
Surgery related & 13 \\
Anaesthesia related & 3 \\
Unknown & 2 \\
\hline
\end{tabular}

Figure 4: Reasons for cancellation

\begin{tabular}{|l|l|}
\hline Medical & Number of Cancellations \\
& \\
\hline Co-morbidities & 19 \\
Cardiac & 10 \\
Respiratory & 1 \\
Infections & 5 \\
Incomplete Pre-op Study & 4 \\
Deranged Coagulation $\quad$ with & 1 \\
$\begin{array}{l}\text { Non- Compliance protocols } \\
\text { Other }\end{array}$ & 1 \\
\hline
\end{tabular}

Figure 5: Medical Causes

\begin{tabular}{|l|l|}
\hline Administrative / logistic & $\begin{array}{l}\text { Number } \\
\text { Cancellations }\end{array}$ \\
\hline Lack of theatre time & 19 \\
Lack of equipment & 6 \\
$\begin{array}{l}\text { Scheduling error - unbooked } \\
\text { patient } \\
\text { Lack of recovery - ICU bed }\end{array}$ & 1 \\
\hline
\end{tabular}

Figure 6: Administrative causes

\begin{tabular}{|l|l|}
\hline Patient related Causes & Number of Cancellations \\
\hline $\begin{array}{l}\text { Patient did not attend } \\
\text { Refusal to undergo surgery } \\
\text { once admitted }\end{array}$ & 2 \\
\hline
\end{tabular}

Figure 7: Patient related causes

\begin{tabular}{|l|l|}
\hline Surgical Causes & Number of Cancellations \\
& \\
\hline Operation no longer indicated & 6 \\
Unavailability of Consultant $\quad 5$ \\
Surgeon \\
Change in diagnosis & 2 \\
\hline
\end{tabular}

Figure 8: Surgical causes

\begin{tabular}{|l|l|}
\hline Anaesthesia Related Causes & $\begin{array}{l}\text { Number } \\
\text { Cancellations }\end{array}$ \\
\hline $\begin{array}{l}\text { Non- compliance with fasting } \\
\text { guidelines }\end{array}$ & 1 \\
$\begin{array}{l}\text { Complication }- \text { anaphylaxis to } \\
\text { antibiotic }\end{array}$ & 1 \\
Other & 1 \\
\hline
\end{tabular}

Figure 9: Anaesthetic causes

\section{Discussion}

The decision to postpone surgery has psychological, social and economic implications. An efficient surgical service should have a low rate of cancellation of operations. If operations are cancelled, the operation theatres are underused; efficiency is jeopardized, waiting lists increases and costs rise. It is a well-known fact that if resources are not properly utilized, the general population suffers especially the lower income groups, who depend more on public or government services for most of their healthcare needs. The cost of facilities and equipment which is underutilized adds to the cost of its services which is ultimately passed on to patients.

In our study, the most common cause of cancellation was coexisting medical problems $38.7 \%$ (41/106). This was the commonest reason in some of the studies done in London. ${ }^{1}$ Majority of elective patients were seen by the anaesthetist only on the day prior to surgery. So the preoperative optimization is done over a short period of time. Studies have shown that preoperative anaesthesia assessment of patients in anaesthetic assessment clinics significantly reduces operative room delays and cancellations. ${ }^{2}$

From the administrative causes of cancellation $17.9 \%(19 / 106)$ were due to lack of theatre time. This was the commonest cause for cancellations in the Indian studies which was about $60 \%{ }^{2,3} \mathrm{We}$ did not analyse the contributing factors for inadequate theatre time. Yet we realize that time management can be optimized by good communication and team effort.

$6 \%(6 / 106)$ of patients did not need surgical interventions though admitted. Some surgical audits have demonstrated that urgent operations reduce the number of available beds, decrease the rate of treatment of elective patients and thereby reduce the efficiency of surgical services. ${ }^{4}$ In addition unnecessary admissions in a surgical unit may cause cancellation of elective cases.

Several delays were due to equipment failure. Equipment malfunction and breakdown is a 
frequent cause for cancellations. This can be minimized by proper maintenance and repair of faulty equipment and informing the surgical team on time to re-schedule patients.

In India the percentage of cancellation vary from $7-30 \%{ }^{2,3,5}$ The commonest causes were patient not attending and lack of theatre time. ${ }^{2}$ In UK around $8 \%$ of scheduled elective operations are cancelled nationally within 24 hours of surgery. In our study, although for a short duration of 4 months done in a specialized unit, $6 \%$ of surgical cases were cancelled on the day of surgery. This is lower than in many other studies.

This study shows that most causes for cancellation of operations are avoidable and steps must be taken to avoid these to enhance the utilization of operation theatre facility.

Our audit had several limitations: Short duration of study (4 months), performed in a specialized single unit, and lack of a proper database of records.

We propose that frequent audits should be carried out at regular intervals to find out effective functioning of the OT, and we plan to do a reaudit in the future to assess the efficiency of the system after the suggestions we made from the analysis.

\section{Conclusion}

The goal of every healthcare team in the new millennium should be to minimize cost of treatment by encouraging cost effectiveness in every aspect of patient care. Efforts should be made to prevent cancellation of elective surgery by careful planning, bearing in mind the local constraints in human and material resources. There is no point in preparing an operation list, which the available manpower and logistics cannot accomplish. Operation lists should be efficiently loaded to avoid under or overutilization of theatre facilities.

\section{Acknowledgements}

We wish to thank Dr. Jayantha Jayasuriya and Dr. Marie Fernando for their encouragement and the guidance to make our audit a success.

\section{References}

1. Morrissey S, Alun -Jones T, Leighton S. Why are operations cancelled? BMJ. 1989; 299:778. http://dx.doi.org/10.1136/bmj.299.6702.778 PMid:2508921 PMCid:1837659
2. Kumar R, Gandhi R. Reasons for cancellation of operation on the day of intended surgery in a multidisciplinary 500 bedded hospital. J AnaesthesiolClinPharmacol. 2012 Jan-Mar; 28(1): $\quad$ 66-69. http://dx.doi.org/10.4103/0970-9185.92442 PMid:22345949 PMCid:3275976

3. Garg R, Bhalotra AR, Bhadoria P et al. Reasons for Cancellation of Cases on the Day of SurgeryA prospective Study. Indian J Anaesth 2009;53:35-9

PMid:20640075 PMCid:2900031

4. Vinukondaiah K, Ananthakrishnan N, Ravishankar M. Audit of operation theatre utilization in general surgery. Natl Med J India, 2000; 13(3):118 PMid:11558108

5. El-Dawlatly AA, Turkistani A, Aldohayan A et al. Reasons of Cancellation of Elective Surgery in a Teaching Hospital. Intern $\mathbf{J}$ Anesthesiol. 2008; $15: 2$. 